Sharif University of Technology
Scientia Iranica
SCIENTIA $\quad \begin{gathered}\text { Transactions D: Computer Science Es Engineering and Electrical Engineering } \\ \text { I RAN I C A }\end{gathered}$

\title{
Determination of Weibull parameters using the standard deviation method and performance comparison at different locations
}

\author{
Y.A. Kaplan* \\ Energy Engineering Department of Osmaniye Korkut Ata University, Osmaniye, Turkey. \\ Received 22 January 2018; received in revised form 4 February 2019; accepted 22 April 2019
}

\section{KEYWORDS \\ Weibull distribution function; \\ Standard deviation method; \\ Wind energy \\ potential.}

\begin{abstract}
This paper analyzed the harmony of the Weibull Distribution Function (WDF) and the real data obtained from three different locations. The Standard Deviation Method (SDM) was used to calculate the coefficients of the WDF in Adana, Osmaniye and Hatay regions. One of the important purposes of this study is to observe how the performance of the SDM changes in regions with different mean wind speeds. The statistical fittings of the calculated and measured hourly wind speed data were evaluated for justifying the performance of the SDM. According to the results, Root Mean Square Error (RMSE), coefficient of determination $\left(\mathrm{R}^{2}\right)$ and Mean Percentage Error (MPE) error analyses tests were used to evaluate the performance of the mentioned method in all three selected regions. The performance of the method mentioned in this study was examined in detail at different regions with different geographic characteristics. For the selected three regions, the performance of the SDM was evaluated at different mean wind speeds varying over the years. In addition, the performance of the selected method in three different regions was examined in detail in those same years and it was observed how geographical factors affected the performance of the method.
\end{abstract}

(C) 2020 Sharif University of Technology. All rights reserved.

\section{Introduction}

In recent years, the need for energy is constantly increasing due to developing technology and an increasing population [1]. The fact that fossil energy sources will become exhausted and their harmful effects on the environment has caused all countries to turn to renewable energy sources [2]. The needs of countries to meet their energy deficits are seriously affecting countries politically and economically. As a consequence of the consumption of limited reserves of fossil fuel and their environmental effects, the attention to renewable energy sources has increased. The capacity

\footnotetext{
*. E-mail address: yalperkaplan@gmail.com
}

usage of wind energy resources is increasing year by year worldwide $[1,3,4]$. Figure 1 shows how global installed wind power capacity has changed from 2004 to 2016. As can be seen from this figure, a similar increase is observed in the installed wind power capacity in recent years. In 2016, total global installed wind power capacity reached $486.75 \mathrm{GW}$ worldwide $[1,5,6]$.

Turkey can be considered a poor country in terms of fossil fuel sources, but Turkey is a country rich in renewable energy sources because of the geographical characteristics of the region. For this reason, wind energy and other renewable energy sources are very important energy subjects in all developing countries such as Turkey [1]. It is anticipated that in 2020, in Turkey, electricity consumption will have increased to 392 TWh with an annual increase of $6.9 \%$ according to the highest scenario, and to $357.4 \mathrm{TWh}$ with an annual 


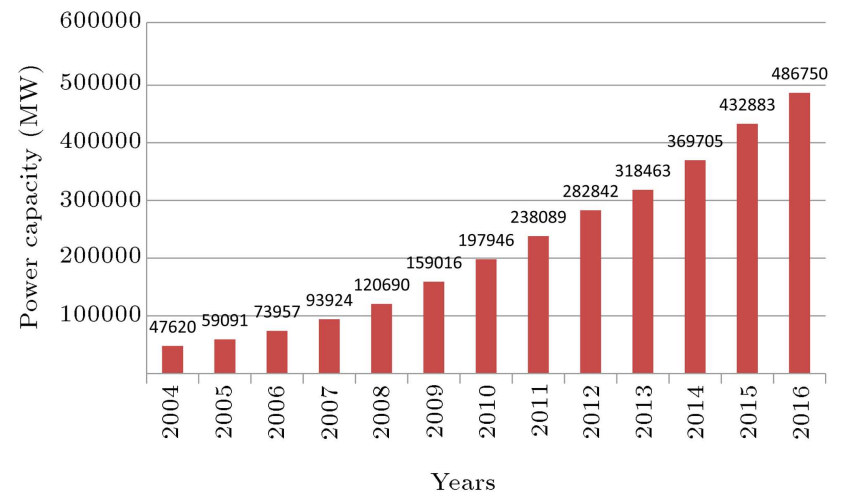

Figure 1. The change of installed wind power in the world according to years.

increase of $5.5 \%$ according to the base scenario. In 2016 , new plants with a total of 5,899 MW were added to the system, and the installed power will have reached $78.497 \mathrm{GW}$ level by the end of 2016 [7]. Currently, the unit cost of energy consumption in Turkey is still high due to the lack of fossil energy resources, and its dependence on foreign aid. . It can be said that a significant increase has been observed in the energy variety and use of renewable energy resources during recent years due to new laws and regulations introduced, especially in the renewable energy investments field. In 2016, if one looks at the overall share of energy sources in electricity production in Turkey, $32.1 \%$ of the electricity generation was obtained from natural gas, $33.9 \%$ from coal, $24.7 \%$ from hydraulic energy, $5.7 \%$ from wind energy, $1.8 \%$ from geothermal energy, and $1.8 \%$ from other resources [7]. It can be said that wind energy is one of the most popular renewable energy resources [1,6]. It is shown in Figure 2 that the installed wind power capacity of Turkey rose by more than $25 \%$ every year between 2011 and 2015. Finally, the power of all installed wind turbines reached $6081 \mathrm{MW}$ level at the end of 2016; a value of around $29 \%$ has been recorded.

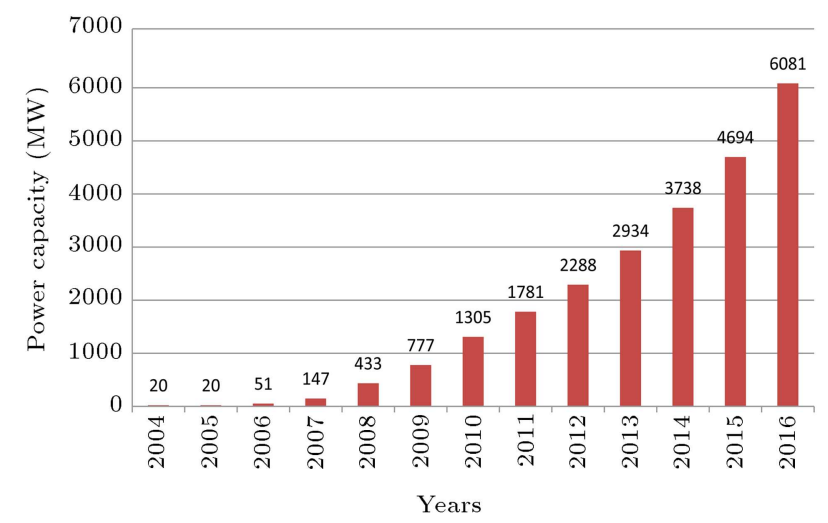

Figure 2. The change of installed wind power in the Turkey according to years.

\section{Literature review}

Many studies have been and are being carried out to determine wind energy potential throughout the world. In most of these studies, the Weibull Distribution Function (WDF) which is compatible with wind speed data is used to estimate the wind energy potential for a selected region. The most important indicator in determining the wind energy potential is the parameters of the WDF. Many different numerical methods were used in the literature to compute these parameters. Some of these studies in the literature are given below.

Chaurasiya et al. [8] estimated the parameters of the WDF with different methods and compared the performance of the used methods at different heights. Soulouknga et al. [9] used the WDF to determine wind potential in selected locations and they determined wind power densities at different altitudes in selected regions. Katinas et al. [10] calculated the dimensionless shape ' $k$ ' coefficient and scale ' $c$ ' coefficient for Lithuania using different methods and analyzed the results. Aries et al. [11] assessed the accuracy of different probability density functions for modeling wind speed distribution in four different regions distributed over Algeria. They used the L-moments method, the maximum likelihood method, the moment method and the power density method, while determining the coefficients of WDF. Usta et al. [12] introduce a new estimation approach that could be used to calculate the parameters of WDF for the estimation of wind power and reviewed the previous estimation methods used to determine the coefficients of WDF. Shoaib et al. [13] evaluated the performance of WDF using real wind data measured at five different altitudes and revealed the wind power potential of the selected region at the Baburband site. Katinas et al. [14] evaluated the application of WDF by summarizing the power density of wind energy in selected regions. They used eight methods to determine the reliability of calculating $t$ shape $k$ and scale $c$ parameters. Aukitino et al. [15] investigated wind energy resource at two locations in Kiribati and, performed and analyzed wind speed, direction, ambient temperature and pressure. Freitas et al. [16] introduced a new approach for evaluating the numerical methods used in determining the coefficients of WDF for estimation of wind energy potential. Azad et al. [17] used different methods to find the coefficients of the WDF and examined how the performance of these methods changed at different heights. Kaoga et al. [18] used five different methods to find the coefficients of the WDF for the Cameroon region, and examined the performance of these methods in different error analysis tests. The coefficients of WDF must be determined to calculate the average wind speed and wind energy potential of the selected region. In this study, the Standard Deviation Method (SDM) method has been used and 
the performance of this method has been investigated in three different regions with different average wind speed and character. Therefore, it has been observed how the performance of the WDF changes with different geographical features and at different mean wind speeds. The performance of the SDM method used to determine the coefficients of WDF has been examined in detail using different error analysis methods.

\section{Wind measurement sites}

The selected regions are given in Figure 3. Adana is situated in the southern part of Turkey which is $23 \mathrm{~m}$ above sea level. The coordinates of Adana are 35.32 east longitude and 37.00 north latitude. Hatay is situated in the southern part of Turkey which is $85 \mathrm{~m}$ above sea level. The coordinates of Hatay: 36.35 east longitude and 36.40 north latitude. Osmaniye is situated in the southern part of Turkey which is $150 \mathrm{~m}$ above sea level. The coordinates of Osmaniye: 36.17 east longitude and 37.21 north latitude. Three separate regions with different average wind speeds have been chosen so that the performance of the given method can be evaluated at different wind speeds.

Turkey should use renewable energy more widely in order to meet the increasing energy demand and should increase the installed wind power capacity. New wind energy targets must be determined and necessary investments should be made. In order to reduce production costs in wind energy and to increase the share of wind in total energy production, it is necessary to establish more efficient systems. Developments in wind turbine technologies are generally aimed at increasing production capacity without compromising physical strength and operating quality.

\subsection{Wind data analyses}

Monthly variations of mean wind speeds in the selected regions are shown in Figure 4 in detail, in all years. This figure is a very important indicator in determining the wind energy characteristics of three locations. As can be seen in the figure, wind characteristics and average wind speeds are different in three selected regions. The reason for choosing three different regions with different wind characteristics is to observe the performance of the SDM used to find the coefficients of the WDF under different wind characteristics and in regions with different mean wind speed.

This study examines the compatibility of the SDM used to find the parameters of WDF at different selected locations with real wind data at a height of ten meters. Figure 5 shows the wind direction intensity of three selected regions [1].

\section{Outline of the methodology}

A variety of distribution functions are used to determine the wind rate distribution. Two-parameter Weibull and Rayleigh distribution functions are the most widely used parameters. As Rayleigh distribution has a single parameter, it is less flexible compared to that of Weibull's, however, estimation of its parameters is much easier. Wind data analysis of a region is a process in which the performance of that region is predicted by utilizing the values that have been previously measured and obtained accordingly $[19,20]$.

\subsection{Determination of weibull parameters}

Different numerical methods are used to calculate the parameters of the WDF. The general expression of the WDF is given in the following equations. The WDF has two parameters; these parameters are dimensionless shape ' $k$ ' coefficient and scale ' $c$ ' coefficient which has the same unit with wind speed $[10,21]$ :

$$
p(v)=\left(\frac{k}{c}\right)\left(\frac{v}{c}\right)^{k-1} \exp \left[-\left(\frac{v}{c}\right)^{k}\right],
$$

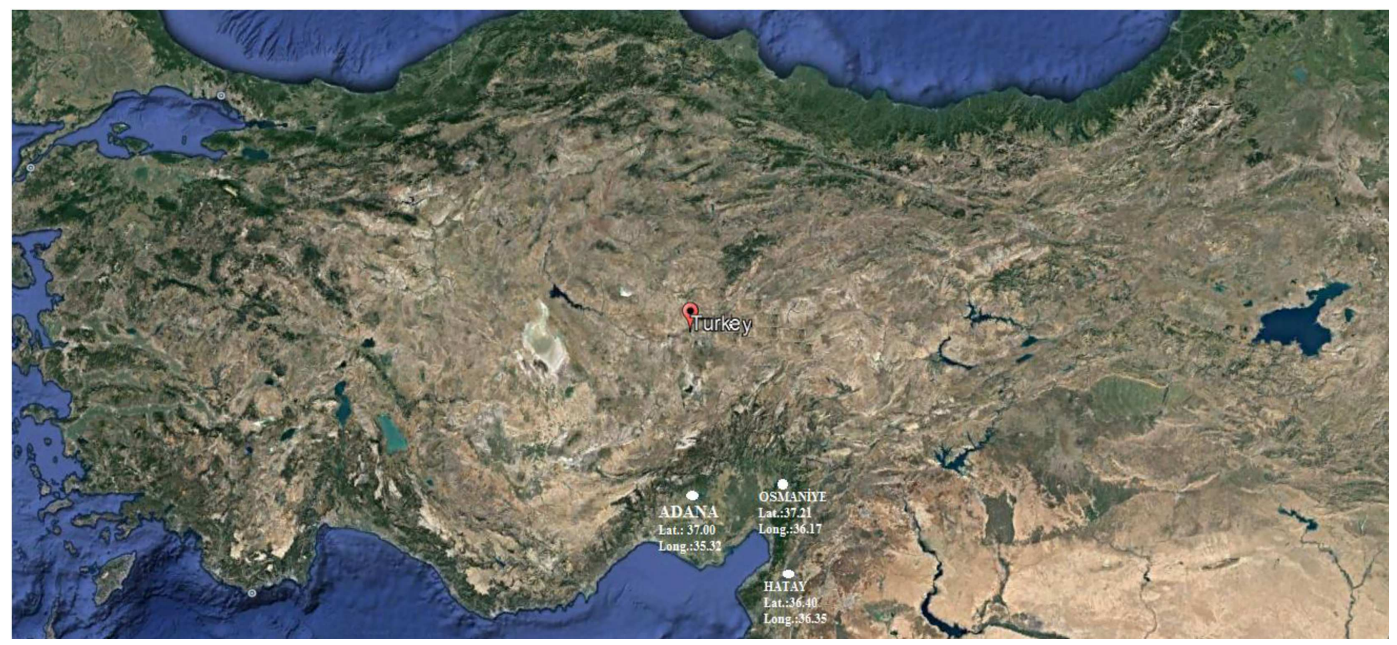

Figure 3. Locations of wind speed observations used in this study. 


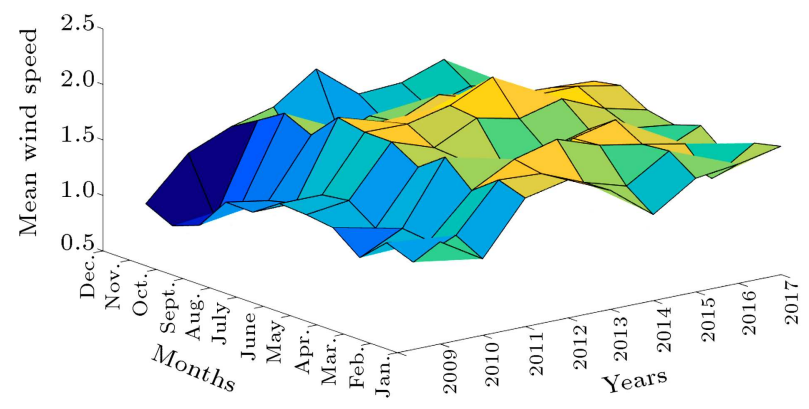

(a) Adana region

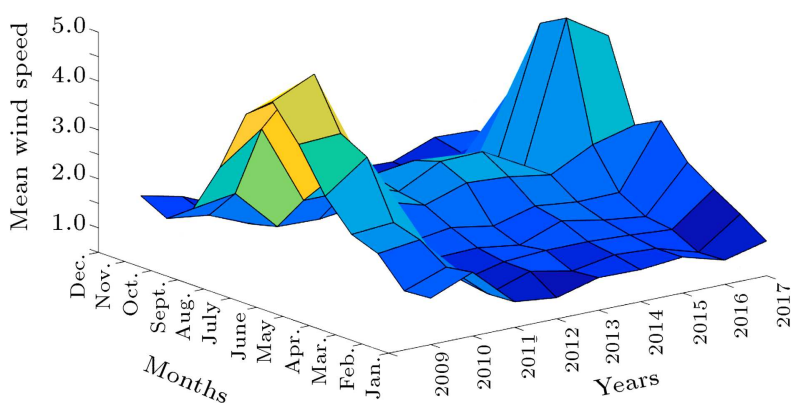

(b) Hatay region

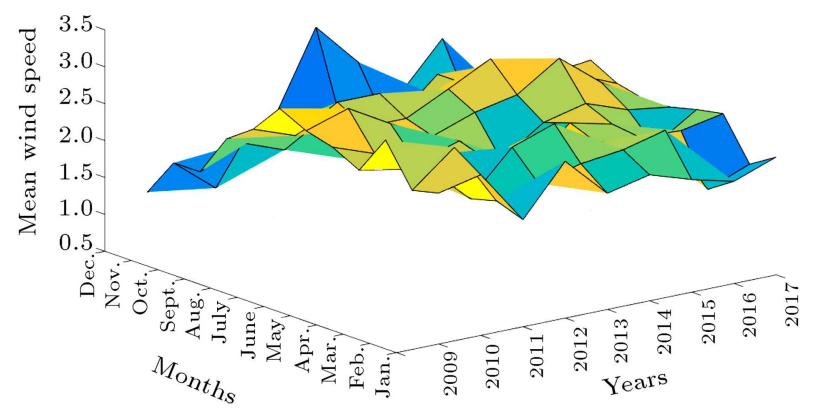

(c) Osmaniye region

Figure 4. The mean wind speed of selected locations according to years and months: (a) Adana region, (b) Hatay region, and (c) Osmaniye region.

$$
P(v)=1-\exp \left[-\left(\frac{v}{c}\right)^{k}\right] .
$$

\subsubsection{Standard Deviation Method (SDM)}

In this method, the average wind speed and the standard deviation values are used to calculate the WDF. The shape ' $k$ ' and the scale ' $c$ ' coefficients can be calculated as in Eqs. (3) and (4) [10,17]:

$$
k=\left(\frac{\sigma}{V_{m}}\right)^{-1.086}
$$

Here, $\Gamma$ is Gamma function [11].

$$
c=\frac{V_{m}}{\Gamma\left(1+\frac{1}{k}\right)} .
$$

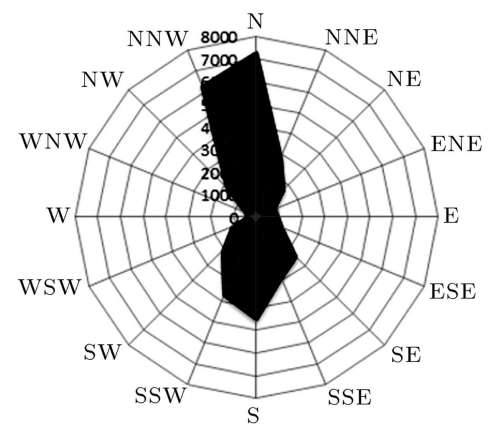

(a)

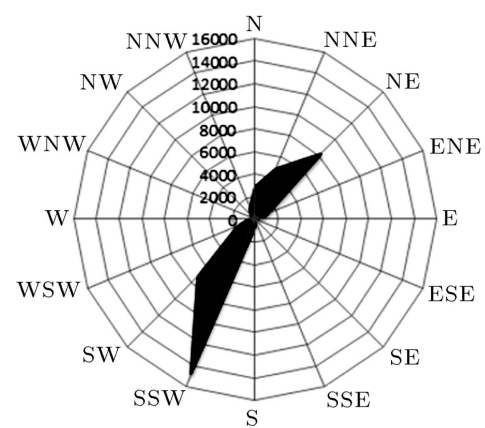

(b)

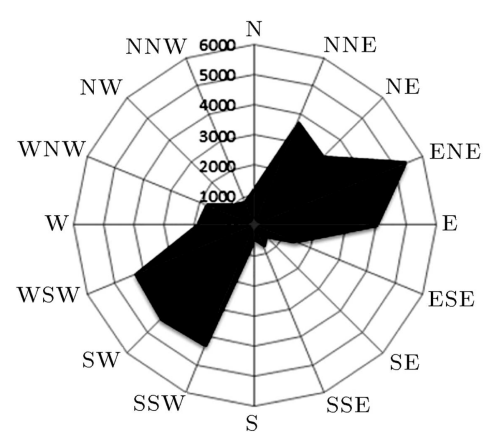

(c)

Figure 5. The wind speed directions of (a) Adana, (b) Hatay, and (c) Osmaniye.

Here, $\sigma$ shows standard deviation and $V_{m}$ average speed [15].

$$
\begin{aligned}
& V_{m}=\frac{1}{n} \sum_{i=1}^{n} v_{i}, \\
& \sigma=\sqrt{\frac{1}{n} \sum_{i=1}^{n}\left(v_{i}-V_{m}\right)^{2} .}
\end{aligned}
$$

In this study, hourly average wind speed data was used to find the dimensionless shape ' $k$ ' parameter and scale ' $c$ ' parameter. In all three regions, wind speed values were measured hourly between the years 2009 and 2017 and about 77.760 wind speed data were used for each region in total. 


\subsection{Wind power calculation}

Nowadays, studies on this subject are undertaken to find wind energy potential at different selected regions. In order to obtain wind energy from a region, firstly the potential of the wind energy of the region must be determined. In general, the energy of the wind is expressed as the following equation [13,21,22]:

$$
P_{A}=\frac{1}{2} \rho A v^{3} .
$$

As can be seen from the above equation, wind speed is the most important input to calculate wind energy potential because wind energy is proportional to the speed of the wind. Small changes in wind intensity can make big and important differences in wind energy. When wind energy farms are established, the most important markers are how often and how long the desired wind intensity occurs. As understood from the equation given above, wind speed directions do not have any factor in determining the potential of wind energy. Firstly, to determine the characterization of wind energy at a selected region, hourly wind speed values and wind directions are examined [23,24,25].

\section{Results and discussion}

The ' $k$ ' coefficient of WDF is a very determinative factor in determining the wind energy characteristics of a selected wind site. The ' $c$ ' coefficient of WDF indicates the wind power potentiality of the selected location. The greater the value of $c$ means the more potential wind sites have. The performance of all used numerical methods in estimating WDF parameters at different locations has been graphically compared. The determined shape and scale coefficients of WDF for the selected three locations are shown in Figure 6, respectively.

One of the most important factors is the dimensionless ' $k$ ' parameter to determine the wind characteristics of the selected regions. The calculated ' $k$ ' parameter is generally greater than ' 1 ' for three regions, so these values indicate that the wind speeds vary at an average level. The smaller values of ' $k$ ' correspond to more variables winds, whereas higher values of ' $k$ ' correspond to less variable winds. The ' $k$ ' value of the Adana region had the lowest value of 1.1786 in 2010 and the highest value of 2.5339 in 2013 . The ' $k$ ' value of the Hatay region had the lowest value of 1.1817 in 2016 and the highest value of 5.4257 in 2010 . The ' $k$ ' value of the Osmaniye region had the lowest value of 1.0028 in 2010 and the highest value of 1.7823 in 2012 . In regions where average wind speed is greater, the $c$ parameter is higher in value. The ' $c$ ' value of the Adana region had the lowest value of $0.7910 \mathrm{~m} / \mathrm{s}$ in 2009 and the highest value of $2.0927 \mathrm{~m} / \mathrm{s}$ in 2013 . The ' $c$ ' value of the Hatay region had the lowest value of $0.8476 \mathrm{~m} / \mathrm{s}$ in 2011 and the highest value of $5.2575 \mathrm{~m} / \mathrm{s}$ in 2016 . The ' $c$ ' value of the Osmaniye region has the lowest value of $1.3359 \mathrm{~m} / \mathrm{s}$ in 2010 and the highest value of $3.3825 \mathrm{~m} / \mathrm{s}$ in 2015 . As can be seen from Figure 5, the scale parameter ' $c$ ' values change monthly and yearly for the selected regions depending on the mean wind speed.

\subsection{Statistical error analysis}

Three different statistical indicators: RMSE (the Root Mean Square Error), $R^{2}$ (analysis of variance) and MPE (Mean Percentage Error), were used to evaluate the performance of the methods used and to compare the results of each method with other methods $[8,12,18,26]$ :

- RMSE:

$$
R M S E=\left[\frac{1}{N} \sum_{i=1}^{N}\left(y_{i}-x_{i}\right)^{2}\right]^{\frac{1}{2}}
$$

- $R^{2}$ :

$$
R^{2}=\frac{\sum_{i=1}^{N}\left(y_{i}-z_{i}\right)^{2}-\sum_{i=1}^{N}\left(y_{i}-x_{i}\right)^{2}}{\sum_{i=1}^{N}\left(y_{i}-z_{i}\right)^{2}} .
$$

- MPE:

$$
M P E=\frac{1}{N} \sum_{i=1}^{N}\left(\frac{x_{i}-y_{i}}{y_{i}}\right) * 100 \% .
$$

The calculated statistical error results were shown in Table 1. The performance of the WDF can be assessed by applying the above statistical tests. When analyzing the compatibility of the used method with actual wind data; the results of RMSE and MPE statistical tests are close to zero, indicating that the performance of SDM is good, and the results of the $R^{2}$ statistical test are close to one, indicating that the performance of SDM is good $[1,7,10]$.

When the table is evaluated in general, it can be said that all statistical error analysis methods give very good results. The results obtained were compared for regions with three different mean wind speed and the values were found to be very close to each other. Although these results vary little from year to year, it shows that this method while determining Weibull coefficients performs very well at different mean wind speed values.

\subsection{Power density assessment}

As known, the difference between the estimated wind energy by the WDF and the calculated wind energy by actual time series data can be used as an indicator to evaluate the performance of the used method. The 

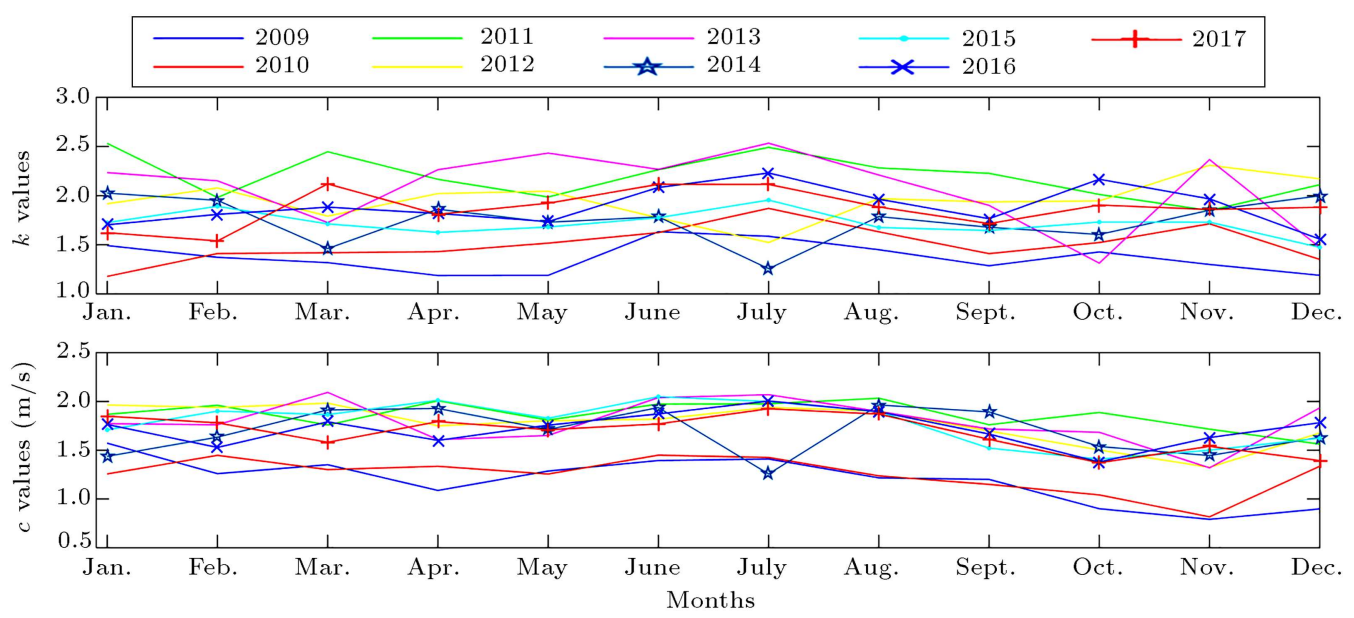

(a)
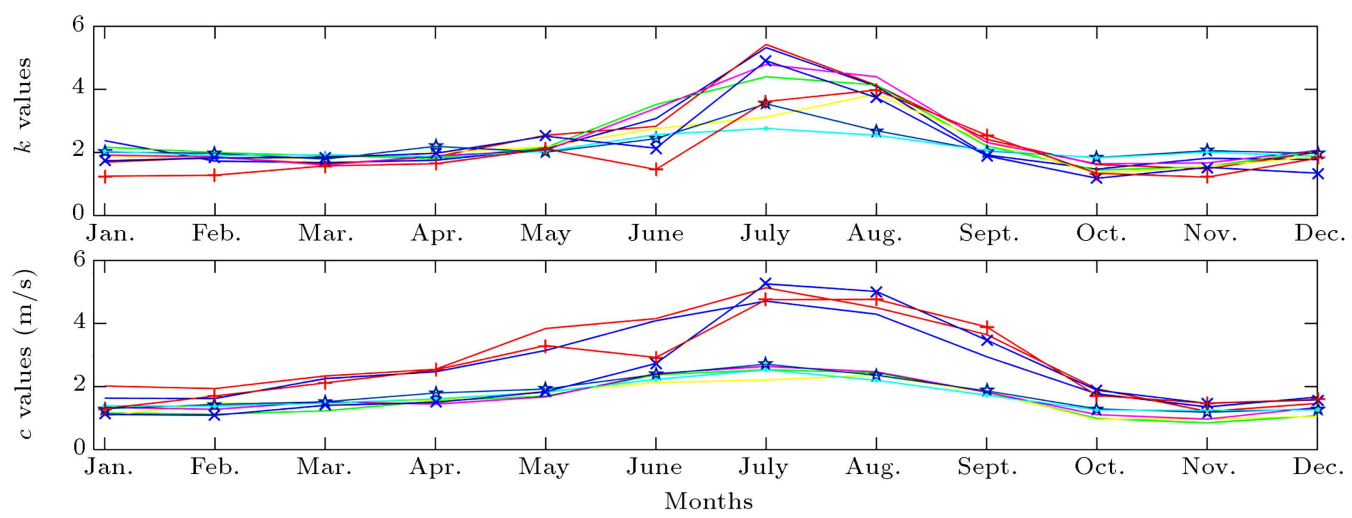

(b)
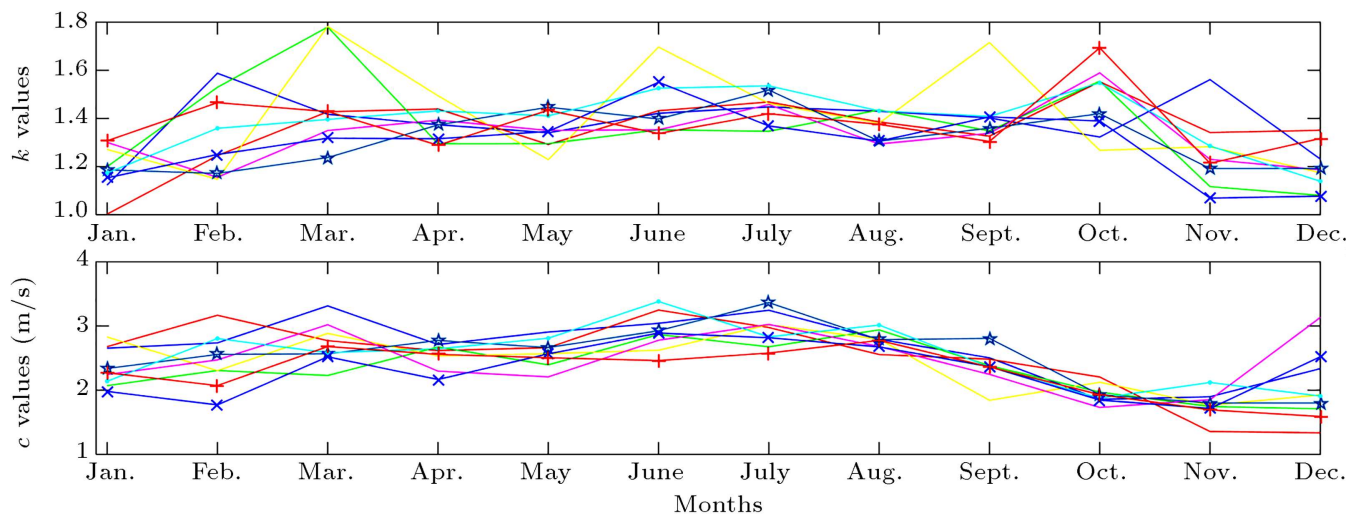

(c)

Figure 6. The determined ' $k$ ' and ' $c$ ' coefficients of Weibull Distribution Function (WDF) for (a) Adana, (b) Hatay, and (c) Osmaniye.

mean wind speed ' $V_{m}$ ' and wind power density ' $P_{m}$ ' can be calculated by the Eqs. (11) and (12) [27,28]:

$$
\begin{aligned}
& V_{m}=\frac{1}{n} \sum_{i=1}^{n} v_{i}, \\
& P_{m}=\frac{1}{2} \rho \overline{v^{3}} .
\end{aligned}
$$

If we replace the actual values in the given equations $\left(\rho=1.223 \mathrm{~kg} / \mathrm{m}^{3}\right)$, the mean wind speed and power can be calculated. The measured mean wind speed and calculated wind power by time series wind speed data are $V_{m}=1.4734$ and $P_{m}=5.0740 \mathrm{~W} / \mathrm{m}^{2}$ for Adana, $V_{m}=1.9111$ and $P_{m}=12.4114 \mathrm{~W} / \mathrm{m}^{2}$ for Hatay, and $V_{m}=2.2735$ and $P_{m}=25.2215 \mathrm{~W} / \mathrm{m}^{2}$ for Osmaniye, respectively. The results in all three regions were obtained using hourly wind speed data between 
Table 1. The results of statistical error tests for three selected regions.

\begin{tabular}{|c|c|c|c|c|c|c|c|c|c|}
\hline \multirow{2}{*}{$\frac{\text { SDM }}{\text { Year }}$} & \multicolumn{3}{|c|}{ Adana } & \multicolumn{3}{|c|}{ Hatay } & \multicolumn{3}{|c|}{ Osmaniye } \\
\hline & $R^{2}$ & RMSE & MPE & $R^{2}$ & RMSE & MPE & $R^{2}$ & RMSE & MPE \\
\hline 2009 & 1.00000 & 0.00006 & 0.00080 & 0.99999 & 0.00272 & 0.03992 & 0.99994 & 0.00091 & 0.05844 \\
\hline 2010 & 1.00000 & 0.00004 & 0.00086 & 0.99999 & 0.00253 & 0.03532 & 0.99973 & 0.00264 & 0.17519 \\
\hline 2011 & 1.00000 & 0.00003 & 0.00067 & 0.99997 & 0.00276 & 0.12728 & 0.99996 & 0.00057 & 0.02940 \\
\hline 2012 & 1.00000 & 0.00004 & 0.00036 & 0.99995 & 0.00306 & 0.18045 & 0.99992 & 0.00093 & 0.01439 \\
\hline 2013 & 0.99253 & 0.01681 & 0.32475 & 0.99997 & 0.00273 & 0.06415 & 0.99995 & 0.00082 & 0.01272 \\
\hline 2014 & 1.00000 & 0.00001 & 0.00018 & 1.00000 & 0.00002 & 0.00031 & 0.99999 & 0.00012 & 0.00516 \\
\hline 2015 & 1.00000 & 0.00002 & 0.00007 & 1.00000 & 0.00000 & 0.00007 & 0.99999 & 0.00020 & 0.00874 \\
\hline 2016 & 1.00000 & 0.00000 & 0.00000 & 1.00000 & 0.00001 & 0.00016 & 1.00000 & 0.00002 & 0.00012 \\
\hline 2017 & 1.00000 & 0.00001 & 0.00020 & 1.00000 & 0.00001 & 0.00002 & 1.00000 & 0.00001 & 0.00004 \\
\hline
\end{tabular}

Table 2. The comparison of calculated and estimated results.

\begin{tabular}{ccccccc}
\hline & \multicolumn{3}{c}{ The obtained results by SDM } & \multicolumn{2}{c}{ Real measured values } \\
\hline $\mathbf{2 0 0 9 - 2 0 1 7}$ & $\boldsymbol{k}$ & $\boldsymbol{c}(\mathbf{m} / \mathbf{s})$ & $\boldsymbol{V}_{\boldsymbol{w}}(\mathbf{m} / \mathbf{s})$ & $\boldsymbol{p}_{\boldsymbol{w}}\left(\mathbf{W} / \mathbf{m}^{\mathbf{2}}\right)$ & $\boldsymbol{V}_{\boldsymbol{m}}(\mathbf{m} / \mathbf{s})$ & $\boldsymbol{P}_{\boldsymbol{m}}\left(\mathbf{W} / \mathbf{m}^{\mathbf{2}}\right)$ \\
\hline Adana & 1.7159 & 1.6484 & 1.4699 & 4.4065 & 1.4734 & 5.0740 \\
Hatay & 1.7199 & 2.1326 & 1.9013 & 9.5102 & 1.9111 & 12.4114 \\
Osmaniye & 1.2973 & 2.4588 & 2.2719 & 24.7511 & 2.2735 & 25.2215 \\
\hline
\end{tabular}

2009 and 2017. The average wind speed ' $V_{w}$ ' and wind power density ' $p_{w}$ ' of WDF can be calculated by the Eqs. (13) and (14) $[1,11,29,30]$ :

$$
\begin{aligned}
& v_{w}=c \Gamma\left(1+\frac{1}{k}\right), \\
& p_{w}=\frac{1}{2} \rho c^{3} \Gamma\left(1+\frac{3}{k}\right) .
\end{aligned}
$$

Both the actual mean wind speed and power values for the three selected locations were calculated and the average speed and power values were calculated using the WDF. The obtained results are given in Table 2. When ' $k$ ' and ' $c$ ' values are examined, it is seen that the most suitable region in terms of wind energy capacity is the Osmaniye region with the highest average wind speed value. It was found that SDM provided a very good performance for three different locations based on the calculated and estimated power densities based on nine-year wind speed data.

\section{Conclusions}

The main objective of this paper is to evaluate the performance of Standard Deviation Method (SDM) for calculating the coefficients of Weibull Distribution Function (WDF) at three different regions with different average wind speed. Three different statistical error tests were used to evaluate the results obtained with SDM. The results of statistical indicators showed that the estimated values for SDM provide close to real wind speed values at three different locations. Based on the results derived from the data obtained over a nine-year period, it was observed that conformity with the real data of the methods used for determining Weibull coefficients may change in line with mean wind speed. The parameters of WDF were evaluated in detail monthly and yearly for the selected regions. The average wind speeds and wind power densities were calculated for all selected regions. It was detected that there might be differences via $R^{2}$, Mean Percentage Error (MPE) and Rot Mean Square Error (RMSE) statistical indicators and evaluations made according to average wind speed and power intensities for the selected locations. Some important outcomes of this article can be summarized as follows:

- The statistical analysis of wind power density and wind speed distribution parameters in the selected regions were investigated using measured wind speed data between 2009 and 2017, and the threedimensional graph is shown in all three regions with monthly average wind speeds changing according to the year;

- The average wind power values for the three regions were estimated using the SDM method. These values are $4.4065 \mathrm{~W} / \mathrm{m}^{2}$ for Adana, $9.5102 \mathrm{~W} / \mathrm{m}^{2}$ for Hatay and $24.7511 \mathrm{~W} / \mathrm{m}^{2}$ for Osmaniye. For the selected three regions, the average power values were calculated from real wind data. These values are $5.0740 \mathrm{~W} / \mathrm{m}^{2}$ for Adana, $12.4114 \mathrm{~W} / \mathrm{m}^{2}$ for 
Hatay and $25.2215 \mathrm{~W} / \mathrm{m}^{2}$ for Osmaniye. When the results were generally evaluated, it can be said that the SDM shows a good performance in the three different regions while determining Weibull coefficients;

- This paper shows the compatibility of SDM with real wind speed data for the selected regions and this study may provide a forecast for investments of wind power to be made in these selected regions;

- When ' $k$ ' and ' $c$ ' coefficients are evaluated for the three different regions, maximum values, which are $k=5.4257$ and $c=5.1315$, are obtained for the Hatay region with the highest average wind speed in 2010;

- According to the statistical error analysis results, it can be said that the SDM to determine the coefficients of WDF has a very good performance in the selected regions. However, it is concluded that the same statistical test does not give the best results in different regions, it cannot be said that this error analysis method gives the best results for the region, as the results vary according to the year and changes in wind speed;

- The distinctive feature of this paper is that no such comprehensive studies have ever been made for SDM, so this detailed paper can contribute greatly to wind energy-related scientific studies.

\section{References}

1. Kaplan, Y.A. "Performance assessment of power density method for determining the weibull distribution coefficients at three different locations", Flow Measurement and Instrumentation, 63, pp. 8-13 (2018).

2. Chaurasiya, P.K., Ahmed, S., and Warudkar, V. "Comparative analysis of Weibull parameters for wind data measured from met-mast and remote sensing techniques", Renewable Energy, 115, pp. 1153-1165 (2018).

3. Agalar, S. and Kaplan, Y.A. "Design of a custom power park for wind turbine system and analysis of the system performance under power quality disturbances", IET Renewable Power Generation, 9(8), pp. 943-953 (2015).

4. Çapika, M., Yılmaz, A.O., and Çavusoglu, I. "Present situation and potential role of renewable energy in Turkey", Renewable Energy, 46, pp. 1-13 (2012).

5. Gabbasa, M., Sopian, K., Yaakob, Z., et al. "Review of the energy supply status for sustainable development in the organization of islamicc conference", Renewable and Sustainable Energy Reviews, 28, pp. 18-28 (2013).

6. GWEC (Global Wind Energy Council), Global wind 2016 report (May 2017).

7. TEIAS. Turkish Electricity Transmission Company (2016). 〈http://www.teias.gov.tr .
8. Chaurasiya, P.K., Ahmed, S., and Warudkar, V. "Study of different parameters estimation methods of Weibull distribution to determine wind power density using ground based Doppler SODAR instrument", Alexandria Engineering Journal, 57, pp. 2299-2311 (2018).

9. Soulouknga, M.H., Doka, S.Y., Revanna, N., et al. "Analysis of wind speed data and wind energy potential in Faya-Largeau, Chad, using Weibull distribution", Renewable Energy, 121, pp. 1-8 (2018).

10. Katinas, V., Gecevicius, G., and Marciukaitis, M. "An investigation of wind power density distribution at location with low and high wind speeds using statistical model", Applied Energy, 218, pp. 442-451 (2018).

11. Aries, N., Boudia, S.M., and Ounis, H. "Deep assessment of wind speed distribution models: A case study of four sites in Algeria", Energy Conversion and Management, 155, pp. 78-90 (2018).

12. Usta, I., Arik, I., Yenilmez, I., and Kantar, Y.M. "A new estimation approach based on moments for estimating Weibull parameters in wind power applications", Energy Conversion and Management, 164, pp. 570-578 (2018).

13. Shoaib, M., Siddiqui, I., Amir, Y.M., et al. "Evaluation of wind power potential in Baburband (Pakistan) using weibull distribution function", Renewable and Sustainable Energy Reviews, 70, pp. 1343-1351 (2017).

14. Katinas, V., Marčiukaitis, M., Gecevičius, G., et al. "Statistical analysis of wind characteristics based on Weibull methods for estimation of power generation in Lithuania", Renewable Energy, 113, pp. 190-201 (2017).

15. Aukitino, T., Khan, M.G., and Ahmed, M.R. "Wind energy resource assessment for Kiribati with a comparison of different methods of determining weibull parameters", Energy Conversion and Management, 151, pp. 641-660 (2017).

16. Freitas de Andrade, C., Maia Neto, H.F., Costa Rocha, P.A., et al. "An efficiency comparison of numerical methods for determining Weibull parameters for wind energy applications: A new approach applied to the northeast region of Brazil", Energy Convers Manage, 86(10), pp. 801-808 (2014).

17. Azad, A.K., Rasul, M.G., and Yusaf, T. "Statistical diagnosis of the best weibull methods for wind power assessment for agricultural applications", Energies, 7, pp. 3056-3085 (2014).

18. Kaoga, D.K., Sergeb, D.Y., Raidandic, D., et al. "Performance assessment of two-parameter weibull distribution methods for wind energy applications in the district of Maroua in Cameroon", International Journal of Sciences, Basic and Applied Research (IJS$B A R), \mathbf{1 7}(1)$, pp. 39-59 (2014).

19. Kaplan, Y.A. "Determination of the best weibull methods for wind power assessment in the southern region of Turkey", IET Renewable Power Generation, 11(1), pp. 175-182 (2017). 
20. Kaplan, Y.A. "Determination of Weibull parameters by different numerical methods and analysis of wind power density in Osmaniye, Turkey", Scientia Iranica, 24(6), pp. 3204-3212 (2017).

21. Kantar, Y.M. and Usta, I. "Analysis of wind speed distributions: wind distribution function derived from minimum cross entropy principles as better alternative to Weibull function", Energy Convers Manage, 49, pp. 962-973 (2008).

22. Akdağ, S.A. and Dinler, A. "A new method to estimate weibull parameters for wind energy applications", Energy Conversion and Management, 50(7), pp. 17611766 (2009).

23. Khan, J.K., Ahmed, F., Uddin, Z., et al. "Determination of Weibull parameter by four numerical methods and prediction of wind speed in Jiwani (Balochistan)", Journal of Basic and Applied Sciences, 11, pp. 62-68 (2015).

24. Islam, M.R., Saidur, R., and Rahim, N.A. "Assessment of wind energy potentiality at Kudat and Labuan, Malaysia using Weibull distribution function", Energy, 36(2), pp. 985-992 (2011).

25. Chang, T.P. "Performance comparison of six numerical methods in estimating Weibull parameters for wind energy application", Appl Energy, 88, pp. 272-282 (2011).

26. Morgan, E.C., Lackner, M., Vogal, R.M., et al. "Prob- ability distributions of offshore wind speeds", Energy Conversion and Management, 52, pp. 15-26 (2011).

27. Mohammadi, K. and Mostafaeipour, A. "Using different methods for comprehensive study of wind turbine utilization in Zarrineh, Iran", Energy Conversion and Management, 65, pp. 463-470 (2013).

28. Gokcek, M., Bayulken, A., and Bekdemir, S. "Investigation of wind characteristics and wind energy potential in Kirklareli, Turkey", Renewable Energy, 32, pp. 1739-1752 (2007).

29. Talha, A., Bulut, Y.M., and Yavuz, A. "Comparative study of numerical methods for determining Weibull parameters for wind energy potential", Renewable and Sustainable Energy Reviews, 40, pp. 820-825 (2014).

30. Usta, I. "An innovative estimation method regarding Weibull parameters for wind energy applications", Energy, 106, pp. 301-314 (2016).

\section{Biography}

Yusuf Alper Kaplan is Associate Professor in the Energy Engineering Department of Osmaniye Korkut Ata University, Osmaniye, Turkey. He received his $\mathrm{PhD}$ degree in Electrical and Electronics Engineering from Anadolu University, Eskişehir, Turkey, in 2014. His main research interests are renewable energy, wind energy, solar energy and power quality. 